\title{
Increased Insulin Sensitivity by High-Altitude Hypoxia in Mice with High-Fat Diet-Induced Obesity Is Associated with Activated AMPK Signaling and Subsequently Enhanced Mitochondrial Biogenesis in Skeletal Muscles
}

\author{
Kang Song ${ }^{a, b, c}$ Yifan Zhang ${ }^{a, b} \quad$ Qin Ga $a^{a, b}$ Zhenzhong Bai ${ }^{a, b}$ \\ Ri-Li Ge ${ }^{a, b}$

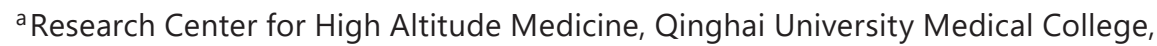 \\ Xining, PR China; ${ }^{b}$ Key Laboratory for Application of High Altitude Medicine in \\ Qinghai Province, Xining, PR China; ' $D$ epartment of Endocrinology, Qinghai Provincial \\ People's Hospital, Xining, PR China
}

\section{Keywords}

High altitude · Ambient hypoxia · Insulin sensitivity · Mitochondrial biogenesis · AMPK signaling $\cdot$ Skeletal muscle

\begin{abstract}
Background: This study aimed to investigate whether and how high altitude-associated ambient hypoxia affects insulin sensitivity in mice fed a high-fat diet (HFD). Methods: Mice were randomly divided into a control group (with normal diet feeding and low-altitude housing), LA/HFD group (with HFD feeding and low-altitude housing), and HA/HFD group (with HFD feeding and high-altitude housing). Results: After 8 weeks, mice in the HA/HFD group showed improved insulin sensitivity-related indices compared with the LA/HFD group. In mice residing in a low-altitude region, HFD significantly impaired mitochondrial respiratory function and mitochondrial DNA content in skeletal muscles, which was partially reversed in mice in the HA/HFD group. In addition, the fatty acid oxidation-related enzyme gene CPT1 (carnitine palmitoyltransferase 1 ) and genes related to mitochondrial biogenesis such as peroxisome proliferator-activated receptor- $\gamma$ coactivator-1 $\alpha(P G C-1 \alpha)$, nuclear respiratory factor 1 (NRF1), and mitochondrial transcription factor A (Tfam) were upregulated in the skeletal muscles of mice housed at high altitude, in comparison to in the LA/HFD group. Furthermore, AMPK (adenosine monophosphate-activated protein kinase) signaling was activated in the skeletal muscles, as evidenced by a higher expression of phosphorylated AMPK ( $p-A M P K)$ and protein kinase B ( $p-A K T)$ in the HA/HFD group than in the LA/HFD group. Conclusion: Our study suggests that high-altitude hypoxia improves insulin sensitivity in mice fed an HFD,
\end{abstract}


Song et al.: High Altitude and Insulin Sensitivity

which is associated with AMPK activation in the skeletal muscle and consequently enhanced mitochondrial biogenesis and fatty acid oxidation. This work provides a molecular explanation for why high altitude is associated with a reduced incidence of insulin resistance in the obese population.

(C) 2020 The Author(s)

Published by S. Karger AG, Basel

\section{Introduction}

Obesity is a global health epidemic that threatens human health and quality of life [1]. It is also a risk factor for metabolic diseases such as type 2 diabetes, cardiovascular disease, and dyslipidemia [2, 3]. Long-term intake of a high-calorie diet, a sedentary lifestyle, and genetic predisposition can lead to obesity, which is characterized by excessive lipids in the blood and insulin resistance [4]. Recently, epidemiological data have shown that the incidence of overweight and obesity is inversely related to altitude, with the prevalence of a metabolic syndrome such as obesity significantly higher among adult individuals living at altitudes of 0-499 m compared to those living at 3,000 $\mathrm{m}$ above sea level [5-7]. Furthermore, individuals living at higher altitudes have a lower fasting glycemia and better glucose tolerance compared with those residing near sea level [8]. However, the molecular basis for this observation is not well understood.

Various environmental factors are thought to differ with prevailing altitudes, and it is generally accepted that most physiological changes that occur in individuals exposed to high elevation are due to ambient hypoxia, referring to a decline in partial pressure of oxygen $\left(\mathrm{pO}_{2}\right)$ decline in inhaled air [8]. Hypoxia occurs when the oxygen demand exceeds the supply, resulting in an insufficient oxygen supply to the tissues and cells. Recent animal studies have demonstrated that adipose tissues become hypoxic in obesity $[9,10]$. As hypoxia is among the prominent regulators of inflammation and reactive oxygen species production [11,12], hypoxia and cellular hypoxic responses may provide mechanistic insights into the causal relationships between obesity and insulin resistance [13]. However, recent investigations demonstrated that hypoxia exposure may improve the metabolic syndrome in obese animals. For example, intermittent exposure to mild hypoxia for 4 weeks in high-fat diet (HFD)-induced type 2 diabetic mice can result in the normalization of the fasting blood glucose, improved whole body insulin sensitivity, and a significant increase in glucose transporter type 4 (GLUT4) translocation to the skeletal muscle [14]. Moderate intermittent hypoxia for 4 weeks ( $12 \mathrm{~h}, 14 \% \mathrm{O}_{2}, 7$ days/week) improves glucose tolerance and increases GLUT4 levels in rats [15]. Prolonged exposure (14 days) to low $\left(5 \% \mathrm{O}_{2}\right) \mathrm{pO}_{2}$ levels tended to increase basal glucose uptake in differentiated human multipotent adipose-derived stem cells [16]. Although these seemingly contradictory effects of hypoxia highlight the important and complicated role of hypoxia on energy balance and metabolism, little is known about the key molecules and signaling pathways that contribute to the relationship between insulin resistance and high-altitude induced ambient hypoxia.

Additionally, mitochondrial dysfunction has been suggested to be a central cause of insulin resistance and associated complications $[17,18]$. Mitochondria are the metabolic centers in a cell, and their primary function is to metabolize glucose and lipids in the body, thereby producing ATP and heat to balance energy supply and demand [19]. A decrease in mitochondrial biogenesis and fatty acid oxidation (FAO) can lead to mitochondrial dysfunction and insulin resistance [20]. Skeletal muscle is a peripheral target organ for insulin action and an important tissue for FAO. Under normal conditions, skeletal muscle is primarily responsible for insulin-stimulated glucose management [21]. As such, metabolic disorders involving the skeletal muscle can significantly impact systemic glucose homeostasis and insulin sensitivity [22]. Mitochondrial biogenesis and lipid metabolism in skeletal muscle are reduced in

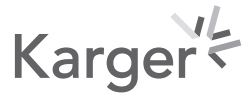


obesity, accompanied by an increase in triglyceride level and decrease in FAO [23], as well as a reduction in the number of muscle mitochondria and activity of related enzymes [24].

AMPK (adenosine monophosphate-activated protein kinase) is a serine/threonine protein kinase in eukaryotic cells that functions as an energy sensor to regulate energy metabolism and maintain mitochondrial homeostasis [25]. It was reported that mice with skeletal muscle-specific knockout of the AMPK $\alpha$ subunit showed decreased mitochondrial biogenesis and function [26]. AMPK stimulates mitochondrial biogenesis and FAO by regulating the transcription factor peroxisome proliferator-activated receptor $\gamma$ coactivator (PGC)-1 $\alpha[27,28]$, which in turn stimulates the expression of downstream nuclear respiratory factor (NRF) 1 and NRF2, and mitochondrial transcription factor A (Tfam). Both NRFs and Tfam can increase the mitochondrial DNA (mtDNA) content, which is a marker for evaluating mitochondrial biogenesis and function $[29,30]$. In fact, patients with insulin resistance and type 2 diabetes showed decreased levels of PGC- $1 \alpha$ and NRF-1 in the muscle tissue, which was associated with a reduction in the number of mitochondria. In addition, carnitine palmitoyltransferase (CPT) 1 on the outer membrane of mitochondria is a rate-limiting enzyme for FAO, which regulates the conversion of long-chain fatty acids in mitochondria.

Finally, a previous study showed that rats in the high-altitude areas exhibit improved insulin and glucose tolerance as well as lower fasting blood glucose levels; however, the enhanced hepatic insulin signaling is thought to be independent of AMPK activation [31]. As people in high-altitude regions often suffer from reduced oxygen availability, and hypoxic conditions activate AMPK to promote mitochondrial biogenesis and FAO, AMPK signaling may play an important role in insulin resistance in obese individuals living in high-altitude regions. However, this has not been experimentally evaluated in obese animals. In the present study, we addressed this question by feeding the mice an HFD and housing them in a lowaltitude region or high-altitude conditions for 8 weeks. We then performed systematical investigation of the effects of high altitude-induced ambient hypoxia on glucose homeostasis, insulin sensitivity, lipid metabolism, mitochondrial function, and AMPK signaling activation in the skeletal muscles of mice fed an HFD.

\section{Materials and Methods}

\section{Experimental Animals}

All animal experiments involving the use of mice were approved by the Animal Protection and Use Institutions Committee of Qinghai University (Xining, China). All experiments were carried out in accordance with the Animal Management Regulations of the Ministry of Health of China. C57BL/ 6 male mice ( $n=45 ; 6$ weeks old) were purchased from Beijing Vital River Laboratory Animal Technology Co. (Beijing, China). After 1 week of normal chow intake, the mice were randomly divided into the following 3 groups ( $n=15$ for each group): low altitude with normal chow (control) group (altitude $50 \mathrm{~m}$ ); low altitude with HFD (LA/HFD) group (altitude $50 \mathrm{~m}$ ); high altitude with HFD (HA/HFD) group (altitude 4,300 m).

The control group was fed a normal diet (Beijing Vital River Laboratory Animal Technology Co.; $19 \mathrm{~g} \%$ protein, $67 \mathrm{~g} \%$ carbohydrate, $4 \mathrm{~g} \%$ fat; $3.85 \mathrm{kcal} / \mathrm{g}$ ); and the LA/HFD and HA/HFD groups were fed an HFD (Diet Formula D12492, Research Diets Inc., New Brunswick, NJ, USA; $26 \mathrm{~g} \%$ protein, $26 \mathrm{~g} \%$ carbohydrate, $35 \mathrm{~g} \%$ fat; $5.24 \mathrm{kcal} / \mathrm{g}$ ). The mice were maintained at the specific pathogen-free facilities at $22 \pm 1{ }^{\circ} \mathrm{C}$ and $45-55 \%$ humidity with a $12 / 12$-h light/dark cycle and ad libitum access to food and water for the duration of the study. Body weight and food intake were measured once per week. Mice were treated for 8 weeks at different altitudes, after which samples were collected and all indicators including mitochondrial respiration were measured at the corresponding local altitude by the same researcher.

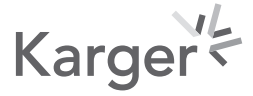


Song et al.: High Altitude and Insulin Sensitivity

\section{Normobaric Normoxia and Hypobaric Hypoxia Environments}

The high altitude laboratory was located in Maduo, China, where the average altitude was $4,300 \mathrm{~m}$, the average barometric pressure was $461 \mathrm{~mm} \mathrm{Hg}(60.7 \mathrm{kPa})$, the $\mathrm{PO}_{2}$ in the breathed air was $88 \mathrm{~mm} \mathrm{Hg} \mathrm{(11.6} \mathrm{kPa),} \mathrm{oxygen} \mathrm{saturation} \mathrm{was} 85 \%$, and $\mathrm{FiO}_{2}$ in the air was $14.07 \%$. The normobaric normoxia environment was located in Tangshan, China, where the average altitude was $50 \mathrm{~m}$, the average barometric pressure was $760 \mathrm{~mm} \mathrm{Hg}(101.3 \mathrm{kPa})$, the $\mathrm{PO}_{2}$ in the breathed air was $149 \mathrm{~mm} \mathrm{Hg}(19.6 \mathrm{kPa})$, oxygen saturation was $97 \%$, and $\mathrm{FiO}_{2}$ in the air was $20.95 \%$.

\section{Energy Efficiency Calculation}

The normal chow diet provided $3.85 \mathrm{kcal} / \mathrm{g}$ energy, while the HFD provided $5.24 \mathrm{kcal} / \mathrm{g}$ energy. Energy efficiency of the control group was calculated according to the formula: energy efficiency = body weight gain $/ 3.85 \times$ food intake; while energy efficiency in the LA/HFD group and HA/HFD group was calculated as body weight gain/5.24 $\times$ food intake.

\section{Glucose Tolerance Test}

At the end of 8 weeks, mice were evaluated with the intraperitoneal glucose tolerance test (GTT; $1.5 \mathrm{~g} / \mathrm{kg}$ glucose) after overnight fasting ( $8 \mathrm{~h}$ ). Blood was collected at $0,15,30,60$, and 120 min after the injection of exogenous glucose (catalog No. G8270; Sigma-Aldrich, St. Louis, MO, USA), and the blood glucose concentration was measured with a standard Ultra Vue Glucometer (Johnson and Johnson Co., New Brunswick, NJ, USA) following the manufacturer's instructions.

\section{Insulin Tolerance Test}

At the end of 8 weeks, the mice were fasted for $4 \mathrm{~h}$ and subjected to the insulin tolerance test (ITT). Human insulin (Novo Nordisk, Denmark; $0.5 \mathrm{U} / \mathrm{kg}$ body weight) was administered by intraperitoneal injection. The blood glucose level was measured before and at 15, 30, 60, and 120 min after insulin injection.

\section{Sample Collections}

At the end of 8 weeks, mice were fasted overnight. Blood was collected by cardiac puncture after anesthetization with pentobarbital (Sigma-Aldrich; $50 \mathrm{mg} / \mathrm{Kg}$, intraperitoneal injection). Partial blood samples were used to determine hemoglobin, red blood cell count and hematocrit levels, while the remaining samples were centrifuged at $2,500 \mathrm{~g}$ for $15 \mathrm{~min}$ at $4{ }^{\circ} \mathrm{C}$ to obtain serum, which was stored at $-20^{\circ} \mathrm{C}$ until use.

Epididymal fat tissue was weighed and fixed with $10 \%$ formalin for subsequent hematoxylin and eosin (HE) staining. Skeletal muscle samples were divided into 5 portions: one of which was used for electron microscopy to analyze the mitochondrial morphology; one for immunohistochemical analysis; 2 portions of fresh tissues were used for RNA and protein detection; and one was placed in mitochondrial permeabilization fluid for analysis of mitochondrial respiratory function.

\section{Blood Biochemical Measurements}

Blood was routinely analyzed with a veterinary automatic blood cell analyzer (BC-5000Vet; Shenzhen Mindray Biomedical Electronics Co., Shenzhen, China). Enzyme-linked immunosorbent assay was used to measure the level of serum insulin (EZRMI-13K; Millipore, Billerica, MA, USA) and serum free fatty acid (Nanjin Jiancheng Bioengineering Institute, Nanjing, China). The serum triglyceride level was measured with a veterinary automatic biochemical analyzer (BC-240Vet; Shenzhen Mindray Biomedical Electronics Co., Shenzhen, China). The homeostatic model assessment of insulin resistance (HOMA-IR) index was calculated 
according to the formula: HOMA-IR $=$ (fasting blood glucose $[\mathrm{mmol} / \mathrm{L}] \times$ serum insulin $[\mathrm{mIU} / \mathrm{L}]) / 22.5$.

\section{Histological and Immunohistochemical Analyses}

Epididymal fat tissue and skeletal muscle were fixed with $4 \%$ paraformaldehyde, embedded in paraffin, and cut into 5- $\mu \mathrm{m}$-thick sections. Epididymal fat tissue sections were stained with HE and examined under a microscope (Olympus, Tokyo, Japan) at 400× magnification. Paraffin-embedded skeletal muscle tissue was deparaffinized, and following antigen retrieval and blocking with $5 \%$ bovine serum albumin (BSA) solution at $37^{\circ} \mathrm{C}$ for $30 \mathrm{~min}$, the sections were incubated overnight at $4{ }^{\circ} \mathrm{C}$ with primary antibodies against phosphorylated (p)-AMPK (Cell Signaling Technology, Danvers, MA, USA; C2535, 1:100 dilution). Biotinylated goat anti-rabbit IgG (Beyotime Biotechnology, Shanghai, China; 1:100 dilution) was applied the following day, and incubated with the sections at $37^{\circ} \mathrm{C}$ for $30 \mathrm{~min}$. Images were acquired at 200× magnification and the integrated optical density and area of protein expression were measured with Image Pro Plus software (Media Cybernetics, Rockville, MD, USA) and used to calculate the mean optical density value.

\section{Transmission Electron Microscopy}

The gastrocnemius muscle was isolated and cut into 10 pieces $(1 \times 1 \times 1 \mathrm{~mm})$ that were fixed in $2.5 \%$ glutaraldehyde at $4{ }^{\circ} \mathrm{C}$. After incubating in $0.1 \mathrm{M}$ phosphate buffer with $1 \%$ osmium tetroxide for $2 \mathrm{~h}$ at $4^{\circ} \mathrm{C}$, the specimens were dehydrated, embedded in epoxy resin, and cut into semi-ultrathin sections (1-2 $\mu \mathrm{m}$ thick) that were stained with methylene blue for 4-5 min. The mitochondrial structure of skeletal muscle cells was examined under a light microscope. The sections were then cut into ultrathin sections (50-70 nm), stained with $3 \%$ uranyl acetate-lead citrate for $15 \mathrm{~min}$, and examined with a transmission electron microscope (H-600 IV; Hitachi, Shanghai, China).

\section{Measurement of Mitochondrial Respiratory Capacity in Permeabilized Skeletal Muscle}

Mitochondrial oxygen consumption was measured in freshly permeabilized skeletal muscle tissue by high-resolution respirometry (Oxygraph 02k; Oroboros Instruments, Innsbruck, Austria) as previously described [32]. Fiber bundles were separated in ice-cool BIOPS buffer composed of $10 \mathrm{~mm}$ Ca-EGTA, $0.1 \mu \mathrm{m}$ free calcium, $20 \mathrm{~mm}$ imidazole, $20 \mathrm{~mm}$ taurine, 50 mM K-MES, $0.5 \mathrm{~mm}$ dithiothreitol, $6.56 \mathrm{~mm} \mathrm{MgCl}$, $5.77 \mathrm{~mm} \mathrm{ATP}$, and $15 \mathrm{~mm}$ phosphocreatine (pH 7.1), and then permeabilized with BIOPS containing saponin $(5 \mathrm{mg} / \mathrm{mL})$. The tissue (3 $\mathrm{mg} / \mathrm{mL}$ ) was resuspended in MiR05 respiratory liquid composed of $110 \mathrm{~mm}$ sucrose, $60 \mathrm{~mm}$ K-lactobionate, $0.5 \mathrm{~mm}$ EGTA, $3 \mathrm{~mm} \mathrm{MgCl}_{2} \bullet 6 \mathrm{H}_{2} \mathrm{O}, 20 \mathrm{~mm}$ taurine, $10 \mathrm{~mm} \mathrm{KH}_{2} \mathrm{PO}_{4}, 20 \mathrm{~mm}$ HEPES, and defatted BSA $(1 \mathrm{~g} / \mathrm{L})$ at $\mathrm{pH}$ 7.1. In the sealed respirometer, different substrates were slowly titrated according to the substrate-uncoupler-inhibitor-titration protocol [32], with $5 \mathrm{~mm}$ malate plus $10 \mathrm{~mm}$ glutamate as complex I substrates and $5 \mathrm{~mm}$ malate plus $0.2 \mathrm{~mm}$ octanoylcarnitine as $\beta$-oxidation substrates. The above steps were performed in the absence of $10 \mathrm{~mm}$ ADP (State 4). State 3 respiration was measured after adding ADP. States 3 and 4 were inhibited by adding $0.5 \mu \mathrm{M}$ rotenone. The respiration control ratio was calculated by dividing the State 3 respiration rate by State 4 respiration rate. The coupling efficiency was calculated as follows to estimate mitochondrial coupling: $\mathrm{j} \approx \mathrm{P}=\mathrm{P}-\mathrm{L} / \mathrm{P}$, where $\mathrm{j} \approx \mathrm{P}=\mathrm{FAO} /$ oxidative phosphorylation (Oxphos) coupling efficiency, where $\mathrm{P}=$ State 3 respiration rate, and $\mathrm{L}=$ State 4 respiration rate. Cytochrome $\mathrm{c}(10 \mu \mathrm{M})$ was added to verify the integrity of the mitochondrial outer membrane. An increase in $\mathrm{O}_{2}$ consumption of more than $15 \%$ following the addition of cytochrome $\mathrm{c}$ indicated that the mitochondrial membrane was destroyed [32], and the data on mitochondrial respiratory capacity were omitted from the analysis if it occurred. 
Table 1. Sequences of PCR primers used in this study

\begin{tabular}{ll}
\hline Name & Primer sequence (5'-3') \\
\hline PGC-1 $\alpha$ & F:TGGAGTGACATAGAGTGTGCTG \\
& R:TTCCGATTGGTCGCTACACC \\
\hline NRF1 & F:TGCATCTCACCCTCCAAACC \\
& R:GAGGCGGCAGCTCTGAATTA \\
\hline Tfam & F:AGGATGATTCGGCTCAGGGA \\
& R:CAGCCATCTGCTCTTCCCAA \\
\hline CPT1 & F:GTCCTGCAACTTTGTGCTGG \\
& R:CAGGTGCTGGTGCTTTTCAC \\
\hline ACC2 & F:TTGAAGGCACAGTGAAGGCTTACG \\
& R:GACGCCATCTTCCTCTGTCAGTTG \\
\hline SREBP-1c & F:GCTACCGGTCTTCTATCAATGA \\
& R:CGCAAGACAGCAGATTTATTCA \\
\hline 18sRNA & F:TTGACGGAAGGGCACCACCAG \\
& R:GCACCACCACCCACGGAATCG \\
\hline
\end{tabular}

Triglycerides in Skeletal Muscles

Triglycerides levels in the skeletal muscles were measured by the GPO-PAP method (Jiancheng Bioengineering Institute, Nanjing, China) according to manufacturer's instructions.

mtDNA Analysis

Total DNA was extracted from skeletal muscle using the TIANamp Genomic DNA kit (catalog No. DP304; Tiangen Biotech, Beijing, China) according to manufacturer's instructions. The mtDNA content was detected by real-time quantitative PCR (qPCR) using the following forward and reverse primers: cytochrome oxidase 1 (Cox1), 5'-CAAAGTATTTAGCTGACTCGCC-3' and 5'-GAAAGATGAATCCTAGGGCTCA-3'; NADH dehydrogenase subunit 1 (ND1), 5'-CTAGCAGAAACAAACCGGGC-3' ${ }^{\prime}$ and $5^{\prime}$-CCGGCTGCGTATTCTACGTT- $3^{\prime}$; and $18 \mathrm{~S}$ rRNA, $5^{\prime}$-TTGACGGAAGGGCACCACCAG-3' and 5'-GCACCACCACCCACGGAATCG-3'. Relative expression levels of the target mtDNA-encoded genes were determined with the $2^{-\Delta \Delta \mathrm{Ct}}$ method [33].

$q P C R$

Total RNA was isolated from skeletal muscle tissue with the RNAsimple Total RNA kit (catalog No. DP419; Tiangen Biotech, Beijing, China), and $2 \mu \mathrm{g}$ of RNA from each sample was used to synthesize cDNA with the Fasting gDNA Dispelling RT SuperMix (catalog No. KR118, Tiangen Biotech, Beijing, China). qPCR was performed via the SYBR Green method using SuperReal Color Premix (catalog No. FP205; Tiangen Biotech, Beijing, China) on a QuantStudio 5 Real-Time PCR system (Thermo Fisher Scientific, Waltham, MA, USA). The primers were synthesized by Sangon Biotech (Shanghai, China), and the sequences are provided in Table 1. Relative expression levels of target genes were determined using the $2^{-\Delta \Delta C t}$ method [33].

Western Blot Analysis

Skeletal muscle tissue $(100 \mathrm{mg})$ was added to $200 \mu \mathrm{L}$ of radioimmunoprecipitation assay buffer containing phenylmethylsulfonyl fluoride (100:1; Beyotime Institute of Biotechnology,

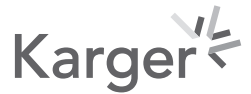




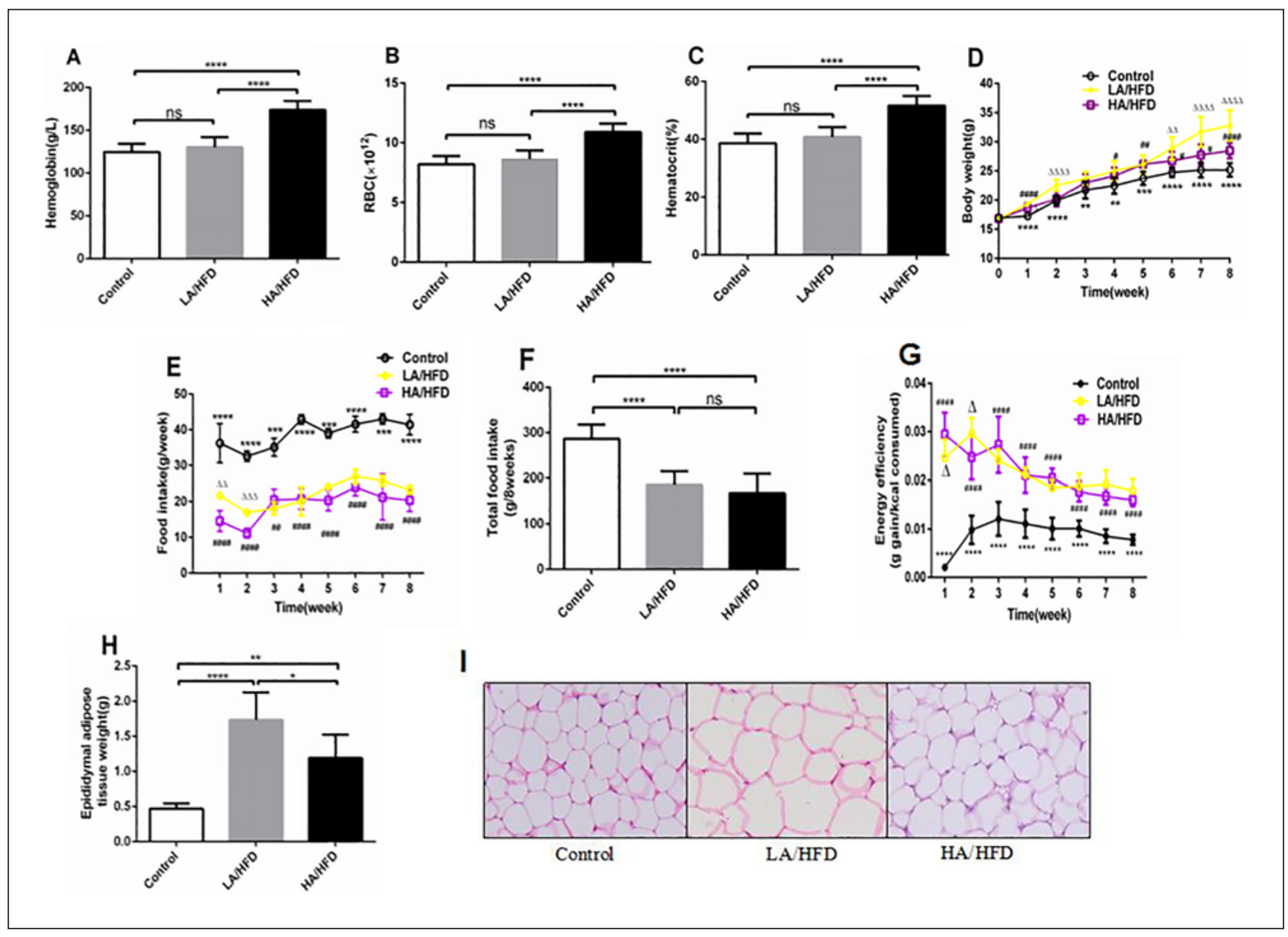

Fig. 1. Effects of high altitude on the hemoglobin level, red blood cell count, hematocrit value, food intake, body weight, adipose tissue weight, and energy expenditure in mice fed an HFD. C57BL/6 male mice were randomly divided into the control group (mice fed with normal diet and housed in a low-altitude area), LA/ HFD group (mice fed an HFD and housed in a low-altitude area), and HA/HFD group (mice fed an HFD and housed in a high-altitude area). At 8 weeks after initiating the indicated feeding and housing, multiple parameters including hemoglobin level (A), red blood cell count (B), and hematocrit value (C) were measured and calculated throughout the 8-week period. Body weight (D) and food intake (E) were measured and calculated throughout the 8-week period. Total food intake (F) was measured over the 8 weeks per mouse per group. Energy efficiency (G) was calculated over the 8-week period. Epididymal fat tissue weight was measured and calculated $(\mathbf{H})$. Representative HE staining of the epididymal fat tissue section is shown (I). Data are expressed as the mean \pm SD of 3 independent experiments $(n=15$ per group, A-G; $n=6$ per group, $\mathbf{H}$; $n=3$ per group, I). A-C, $\mathbf{F}, \mathbf{H}^{*} p<0.05$, ${ }^{* *} p<0.01$, ${ }^{* * * *} p<0.0001$, ns, non-significant (one-way analysis of variance followed by Tukey's multiple comparisons test). D, E, G ** $p<0.01,{ }^{* * *} p<0.001,{ }^{* * * *} p<0.0001$, for the control group vs. LA/HFD group; ${ }^{\#} p<0.05$, ${ }^{\# \#} p<0.01,{ }^{\# \# \# ~} p<0.001$, \#\#\#\# $p<0.0001$ for the control group vs. HA/HFD group; ${ }^{\Delta} p<0.05,{ }^{\Delta \Delta} p<0.01,{ }^{\Delta \Delta \Delta \Delta} p<0.0001$ for the LA/HFD group vs. HA/HFD group (oneway analysis of variance followed by Tukey's multiple comparisons test).

Shanghai, China) and homogenized. The sample was centrifuged at 12,000 rpm for $20 \mathrm{~min}$ at $4{ }^{\circ} \mathrm{C}$. The protein concentration was determined with the bicinchoninic acid assay (Pierce ${ }^{\mathrm{TM}}$ BCA Protein Assay Kit, catalog No. 23225; Thermo Fisher Scientific, Waltham, MA, USA) according to the manufacturer's instructions. Proteins were separated by SDS-PAGE (sodium dodecyl sulfate-polyacrylamide gel electrophoresis) and transferred to a PVDF (polyvinylidene difluoride) membrane that was blocked with $5 \%$ skimmed milk at room temperature 
Song et al.: High Altitude and Insulin Sensitivity

for $2 \mathrm{~h}$ and incubated overnight at $4{ }^{\circ} \mathrm{C}$ with primary antibodies against the following proteins: AMPK $\alpha$ (catalog No. 5831), p-AMPK $\alpha$ (2535), AKT (9271), p-AKT (9271), PGC-1 $\alpha$ (ab54481; Abcam), and $\beta$-actin (4970; all from Cell Signaling Technology except anti-PGC- $1 \alpha$ antibody, and all antibodies were used at 1:1 000 dilution). The membrane was washed 5 times with $1 \times$ Tris-buffered saline supplemented with $0.1 \%$ Tween-20, and incubated for $1 \mathrm{~h}$ at room temperature with horseradish peroxidase-conjugated anti-rabbit-IgG (catalog No. 7074, 1:2000 dilution; Cell Signaling Technology, Danvers, MA, USA). Protein bands were detected by enhanced chemiluminescence (Thermo Fisher Scientific). The band intensities were quantified by densitometry using ImageJ software (version 1.49; National Institutes of Health, Bethesda, MA, USA).

\section{Statistical Analysis}

Data were analyzed using GraphPad Prism 5 software (GraphPad Software Inc., San Diego, CA, USA), and are expressed as the mean \pm SD. Differences among groups were evaluated by one-way analysis of variance followed by Tukey's multiple comparisons test unless stated otherwise. Significance was defined as $p<0.05$.

\section{Results}

High Altitude Elevated Hemoglobin (Hb), Red Blood Cell (RBC) Count, and Hematocrit Levels in Mice Fed with HFDs

First, we evaluated the Hb level, RBC count, and hematocrit values in mice after being fed experimental diets and housed in a location with low or high altitude for 8 weeks. These 3 parameters were not significantly different between the control and LA/HFD groups. However, all values were significantly elevated in the HA/HFD group compared to the other 2 groups (Fig. $1 \mathrm{~A}-\mathrm{C}$ ). These results indicated that housing at a high altitude can increase the levels of Hb, RBCs, and hematocrit in mice fed an HFD.

High Altitude Reduced Body and Adipose Tissue Weight Gain in Mice Fed an HFD, but Did Not Change Food Intake and Energy Expenditure

Significant differences were not observed in the body weight of control, LA/HFD, and HA/HFD mice at the experimental starting point (Fig. 1D). However, after 8 weeks, compared with the control group, the final body weight increased significantly in the LA/HFD group, while the HA/HFD group showed significantly lower values than the LA/HFD group $(p<0.05$; Fig. 1D). For the first 2 weeks, food intake in the HA/HFD group was decreased significantly

Fig. 2. Effects of high altitude on glucose homeostasis, insulin sensitivity, and lipid metabolism in mice fed an HFD. C57BL/6 male mice were randomly divided into the control group (mice fed a normal diet and housed in a low-altitude area), LA/HFD group (mice fed an HFD and housed in a low-altitude area), and HA/ HFD group (mice fed an HFD and housed in a high-altitude area). At 8 weeks after initiating the indicated feeding and housing, glucose and lipid metabolism-related parameters including blood glucose level in GTT (A), area under the curve in the GTT (B), blood glucose level in ITT (C), area under the curve in the ITT (D), serum fasting insulin level (E), HOMA-IR index (F), serum triglyceride level (G), and free fatty acid level (H) were measured and calculated. Data are expressed as the mean \pm SD $(n=13-15$ per group, A, B; $n=6$ per group, C, D; $n=7-9$ per group, E, F; $n=6$ per group, G, H). A, C ${ }^{* *} p<0.01,{ }^{* * *} p<0.001,{ }^{* * * *} p<0.0001$, for the LA/HFD group vs. HA/HFD group; ${ }^{\Delta} p<0.05$, for the control group vs. HA/HFD group; ${ }^{\#} p<0.05$, \#\#\#\# $p<$ 0.0001 for the control group vs. LA/HFD group. B, D, E-H: ${ }^{*} p<0.05$, ${ }^{* *} p<0.01$, ${ }^{* * *} p<0.001$, ${ }^{* * * *} p<0.0001$; ns, non-significant (one-way analysis of variance followed by Tukey's multiple comparisons test, A, B, E-H; independent samples $t$ test, C, D).

(For figure see next page.)

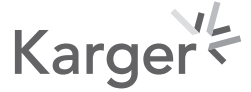



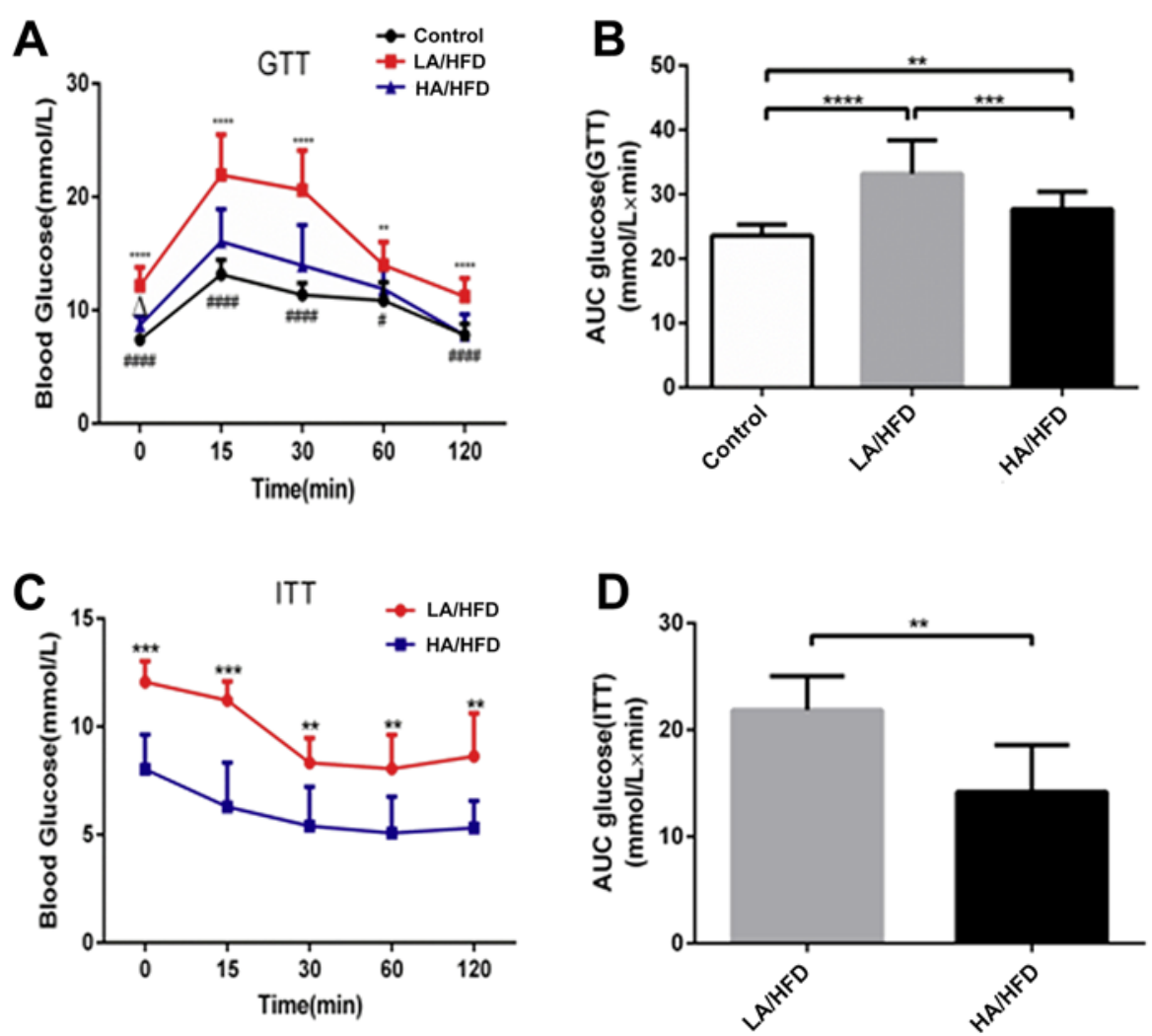

E

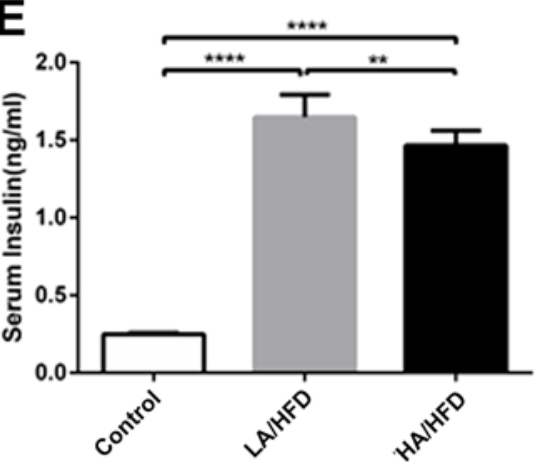

F

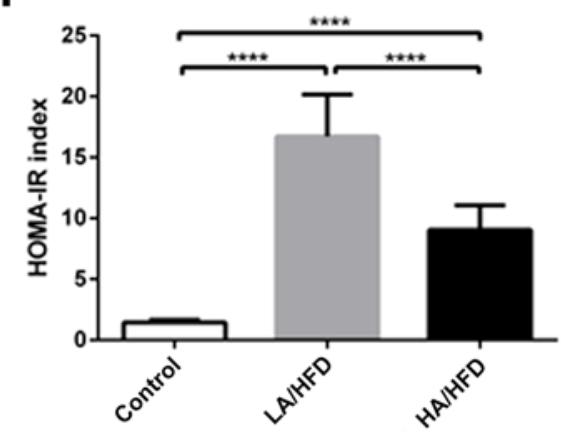

G

H
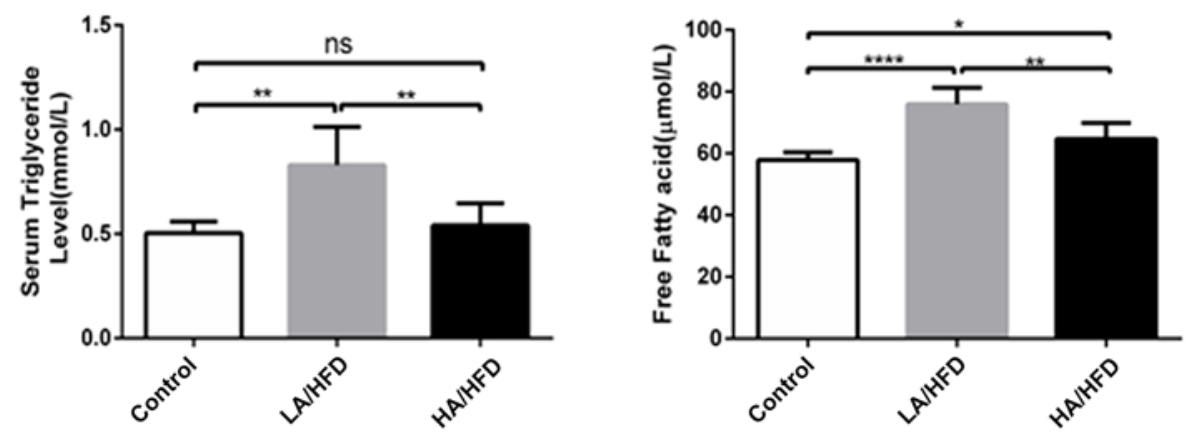
Song et al.: High Altitude and Insulin Sensitivity

compared to the LA/HFD group; however, food intake in the HA/HFD group improved gradually from 2 weeks ( $p<0.05$; Fig. 1E). No differences were observed in the average total food intake between the LA/HFD group and HA/HFD group ( $p>0.05$; Fig. 1 F). There were no differences in energy efficiency between the LA/HFD and HA/HFD groups after 2 weeks ( $p>$ 0.05 ; Fig. $1 \mathrm{G}$ ). Compared with the control group, the epididymal fat weight and adipocyte cell size were significantly increased in the LA/HFD group, whereas these parameters in the HA/ HFD group were significantly lower than those in the LA/HFD group (Fig. 1H, I), suggesting that the effect of high altitude on body and adipose tissue weight gain was not because of decreased food intake and energy efficiency.

High Altitude Ameliorated the Dysregulation of Glucose Homeostasis, Insulin Sensitivity, and Lipid Metabolism in Mice Fed HFDs

To investigate the effects of altitude on blood glucose homeostasis, insulin sensitivity, and lipid metabolism in mice with HFD-induced obesity, we evaluated glucose and insulin tolerance in mice housed in low-altitude and high-altitude areas for 8 weeks. The results of the GTT assay showed that the blood glucose content and area under the curve were significantly higher in the LA/HFD group than in the control group at each detection time point (Fig. 2A, B). Furthermore, the GTT and ITT assays showed that the blood glucose content and area under the curve were significantly lower in mice housed at high altitude compared to those housed in the low-altitude area under the same HFD feeding conditions (Fig. 2A-D). Similar to the above phenomenon, the serum insulin concentration and HOMA-IR were lower in the HA/HFD group than in the LA/HFD group (Fig. 2E, F), as were serum triglyceride and free fatty acid levels (Fig. 2G, H). Collectively, these results indicate that high altitude improved the dysregulation of glucose homeostasis, insulin sensitivity, and lipid metabolism in mice subjected to HFD feeding.

\section{High Altitude Improved the Mitochondrial Oxidative Metabolism of Skeletal Muscle in} Mice Fed an HFD

As high altitude exposure has been well recognized as a hypoxia condition that significantly affects the mitochondrial oxidative metabolism [34, 35], we examined the mtDNA content, mitochondrial morphology, and respiratory function in skeletal muscle from mice fed an HFD and housed in low- and high-altitude areas. The mitochondria morphology in the skeletal muscle of each group was firstly examined by transmission electron microscopy. Compared with the control group, the LA/HFD group contained mitochondria showing irregularities and marginal shrinkage. In addition, the number and size of mitochondria was decreased, and the size was decreased in the skeletal muscle of mice in the LA/HFD group. When the HFD-fed mice were housed at high altitudes, the mitochondrial morphological characteristics in skeletal muscles were similar to those of mitochondria in the control group (Fig. 3A). Furthermore, the results of the mtDNA assay indicated that the levels of mtDNA ND1 and COX1 in the LA/HFD group were significantly lower than those in the control group, while compared to the LA/HFD group, the HA/HFD group showed significantly increased mtDNA content of ND1 and COX1 in the skeletal muscles (Fig. 3B). To determine whether the observed differences in mitochondria affected the respiration function of the skeletal muscles, we used high-resolution respirometry to measure the respiratory control ratio and coupling efficiency in permeabilized muscle fibers. The FAO respiratory control ratio, FAO coupling efficiency, Oxphos respiratory control ratio, and Oxphos coupling efficiency in the LA/HFD group were significantly lower than those in the control group, whereas the above 4 indicators in the HA/ HFD group were significantly higher than those in the LA/HFD group and comparable to those in the control group (Fig. 3C-F). These results indicated that high altitude improved mitochondrial respiration in the skeletal muscles of mice fed an HFD. 


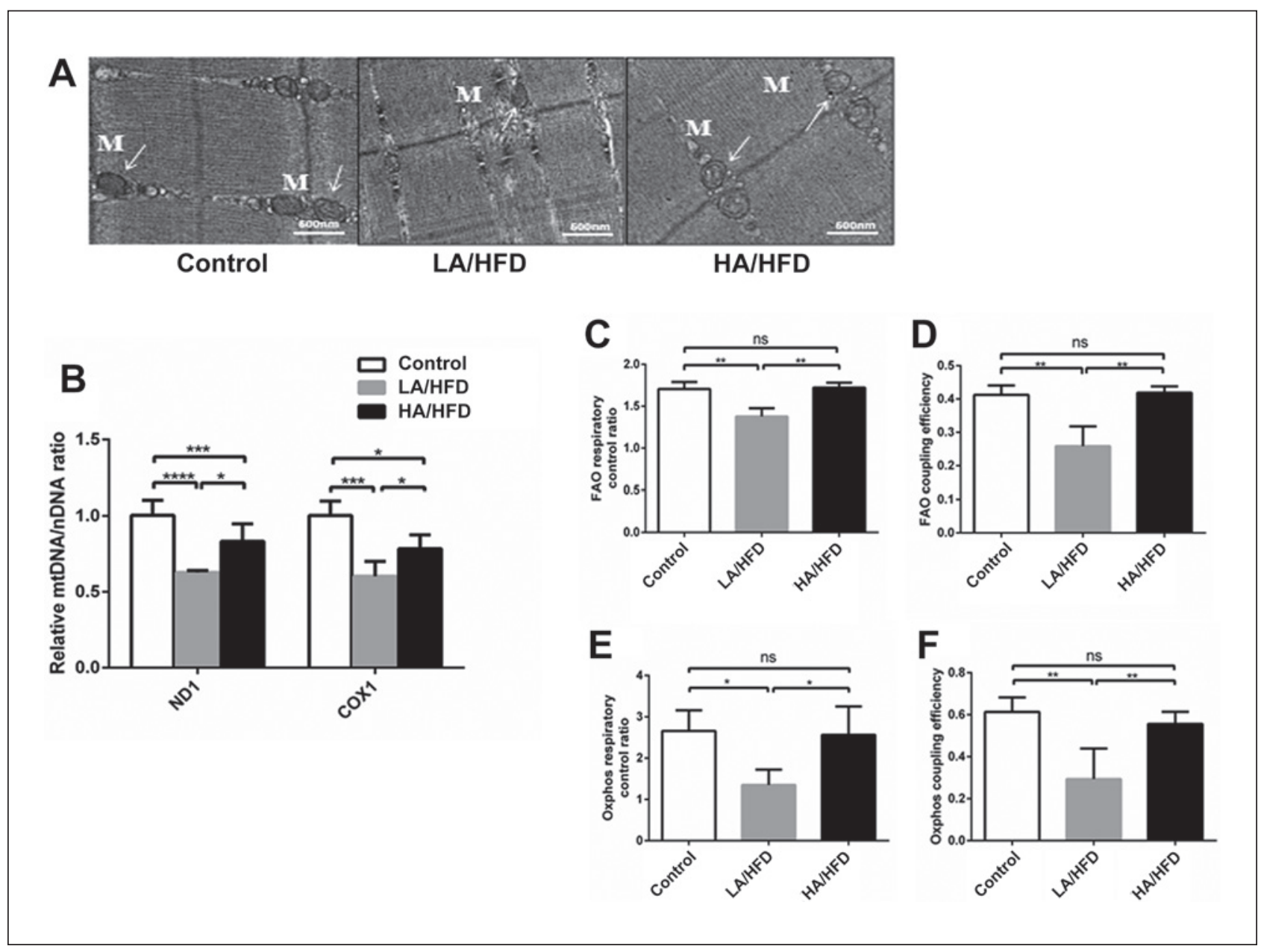

Fig. 3. Effects of high altitude on mitochondrial morphology, mtDNA content, and respiratory function in skeletal muscles from mice fed an HFD. C57BL/6 male mice were randomly divided into the control group (mice fed a normal diet and housed in a low-altitude area), LA/HFD group (mice fed an HFD and housed in a low-altitude area), and HA/HFD group (mice fed an HFD and housed in a high-altitude area). The mice were sacrificed after 8 weeks. A Representative transmission electron microscopy images showing the morphology of mitochondria in mice skeletal muscles from 3 groups. Magnification, $\times 30,000$. Arrows indicate mitochondria (M). B Relative copy numbers of mtDNA ND1 and COX1 were determined by qPCR. C-F Summaries of the FAO respiratory control ratio (C), FAO coupling efficiency (D), Oxphos respiratory control ratio (E), and Oxphos coupling efficiency (F) in permeabilized skeletal muscles from mice in 3 groups. Data are expressed as the mean \pm SD $(n=3$ per group, A; $n=6$ per group, $\mathbf{B} ; n=3-5$ per group, $\mathbf{C}-\mathbf{F}) .{ }^{*} p<0.05,{ }^{* *} p<$ $0.01,{ }^{* * *} p<0.001,{ }^{* * * *} p<0.0001$; ns, non-significant (one-way analysis of variance followed by Tukey's multiple comparisons test).

\section{Beneficial Effects of High Altitude on Mitochondrial Biogenesis and FAO in Skeletal} Muscles from HFD-Fed Mice Were Associated with Enhanced AMPK and AKT Signaling

As p-AMPK activity affects muscle mitochondrial biogenesis and FAO [36], we explored the contribution of AMPK signaling and the activation of the insulin signaling pathway (indicated by the p-Akt/Akt ratio) [37], to high-altitude mediated improvement on mitochondrial oxidative metabolism in the skeletal muscles of mice fed an HFD. At low altitudes, HFD feeding did not significantly affect $\mathrm{p}$-AMPK protein expression and the $\mathrm{p}$-AMPK/AMPK ratio in mice skeletal muscles, but significantly decreased the p-Akt protein level and p-Akt/Akt ratio (Fig. 4A, E). The p-AMPK protein level, p-AMPK/AMPK ratio, p-Akt protein level, and 
A
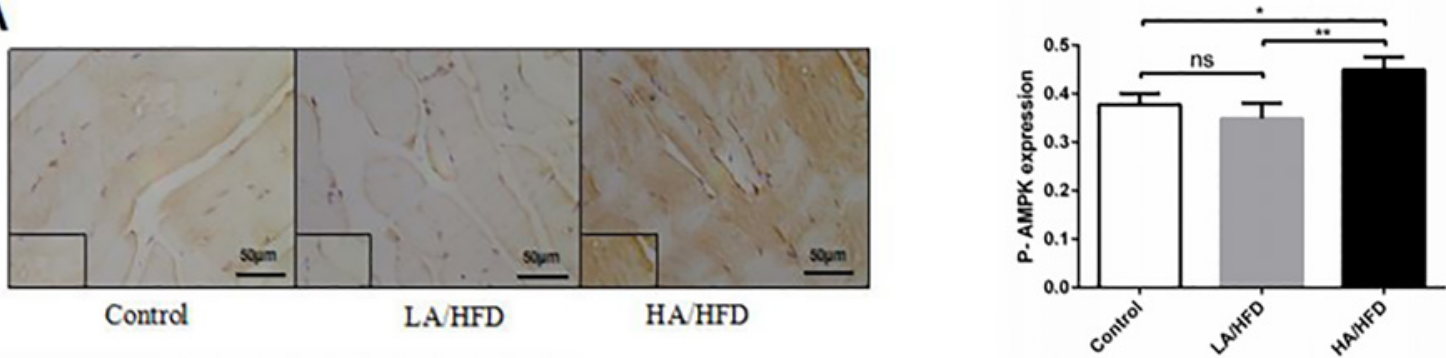

B
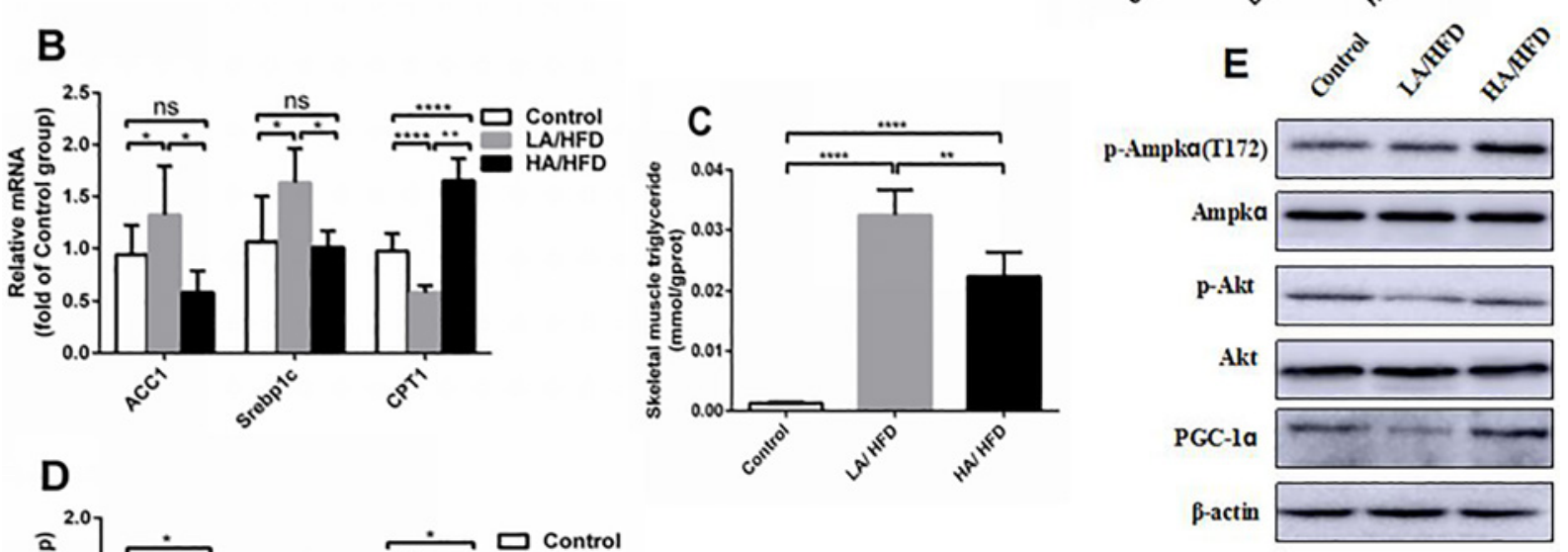

D
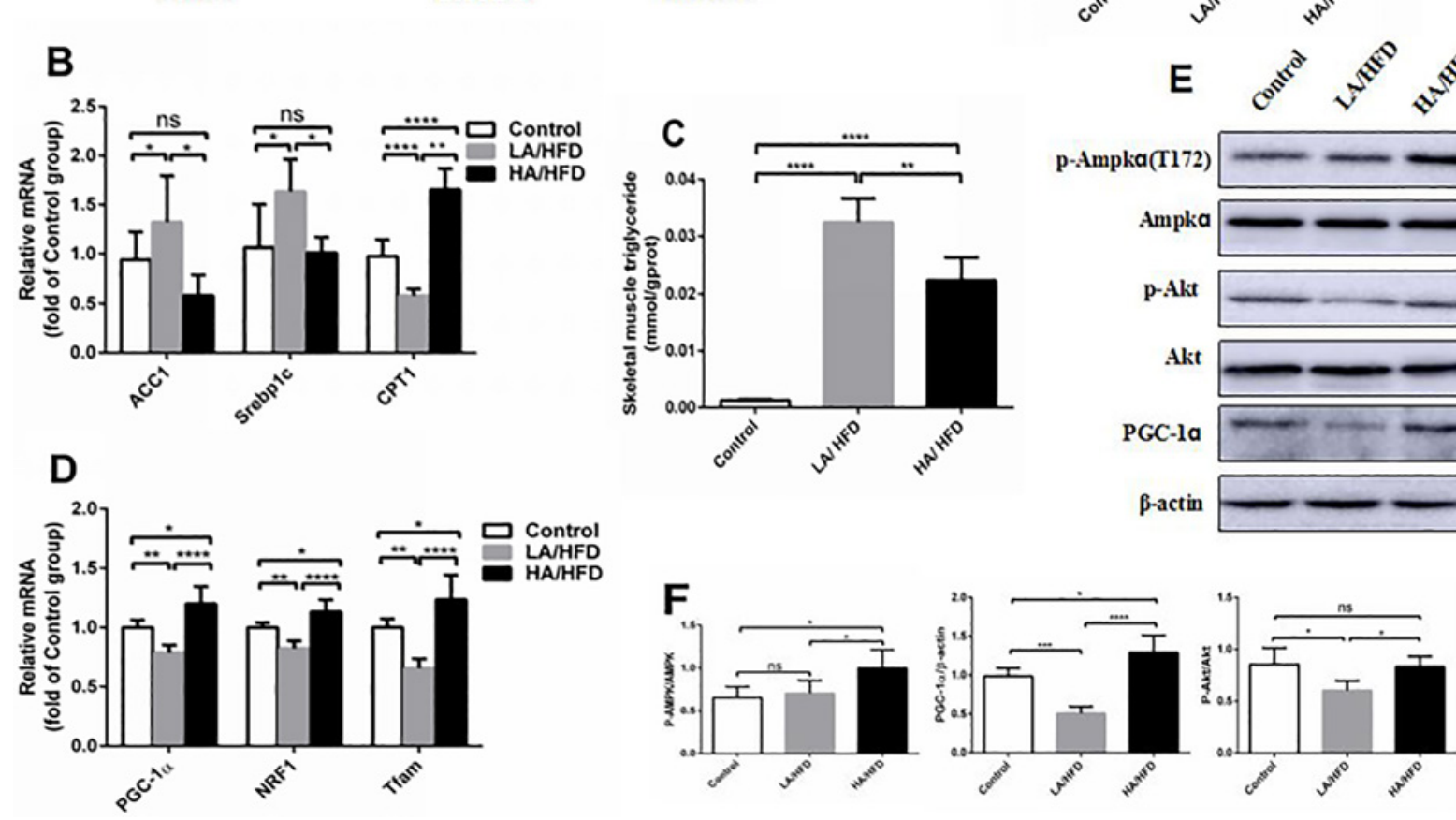

Fig. 4. Effects of high altitude on p-AMPK levels, expressions of FAO/mitochondrial biogenesis-associated genes, and p-AKT levels in skeletal muscles from mice fed an HFD. A-F C57BL/6 male mice were randomly divided into the control group (mice fed a normal diet and housed in a low-altitude area), LA/HFD group (mice fed an HFD and housed in a low-altitude area), and HA/HFD group (mice fed an HFD and housed in a high-altitude area). The mice were sacrificed after 8 weeks. A Immunohistochemical detection of p-AMPK in skeletal muscles of mice in the 3 groups. Representative images show the staining intensity of p-AMPK in skeletal muscles, and the relative intensity of p-AMPK expression is summarized. B mRNA levels of lipid synthesis-related genes (ACC2, Srebp1c) and lipid oxidation-related genes (CPT1) were determined by qPCR. C Triglycerides were measured in the skeletal muscle. D mRNA levels of mitochondrial biogenesis-related genes were determined by qPCR. E, F Immunoblot analysis of p-AMPK, AMPK, p-Akt, Akt, and PGC- $1 \alpha$ levels in skeletal muscles of 3 groups. Representative Western blot images (E) were from 5 independent experiments with similar results, and the relative levels of indicated proteins are summarized (F). Data are expressed as the mean \pm SD ( $n=3$ per group, A; $n=5$ per group, B, D; $n=4$ per group, C; $n=5$ per group, E, F). ${ }^{*} p<0.05,{ }^{* *} p<0.01,{ }^{* * *} p<0.001,{ }^{* * * *} p<0.0001$; ns, non-significant (one-way analysis of variance followed by Tukey's multiple comparisons test).

p-Akt/Akt ratio were significantly higher in the HA/HFD group than in the LA/HFD group (Fig. 4A, E, F). Furthermore, the expression of CPT1, a key gene in the FAO in the skeletal muscle, as well as key genes in fat synthesis $(A C C 2$, Srebp1c) were determined. The results suggested that, compared to the LA/HFD group, the expression level of CPT1 was increased in the HA/HFD group, whereas the expression levels of ACC2 and Srebp1c were decreased 
(Fig. 4B). Additionally, the level of triglycerides in the skeletal muscle, compared to in the LA/HFD group, were decreased in the HA/HFD group (Fig. 4C). Therefore, it can be postulated that lipolysis in the skeletal muscle may be increased whereas lipid deposition was decreased.

In addition, compared to the control group, the LA/HFD group showed significantly reduced mRNA levels of the mitochondrial biogenesis-related genes PGC- $1 \alpha, N R F 1$, and Tfam. In HFD-fed mice housed under high-altitude hypoxia conditions, the expression levels of these genes in the skeletal muscles were significantly higher than those in HFD-fed mice in the low altitude area (Fig. 4D). Furthermore, a similar expression pattern of PGC- $1 \alpha$ protein was also observed in the 3 groups (Fig. 4F). Taken together, these results suggest that the beneficial effects of high altitude on mice with HFD-induced obesity are associated with enhanced AMPK signaling and insulin sensitivity in the skeletal muscle.

\section{Discussion}

In the present study, we evaluated the influence of high-altitude hypoxia on AMPK activity, lipid metabolism mitochondrial biogenesis, and the insulin signaling pathway in mice fed an HFD. We found that under the same HFD feeding conditions, mice housed at high altitude with ambient hypoxia showed increased insulin sensitivity compared to those housed at a low altitude. Moreover, the mitochondrial biogenesis in skeletal muscles was significantly increased under ambient hypoxia conditions in mice fed an HFD and housed at high altitude. Further investigation demonstrated that these effects were associated with the upregulation of p-AMPK protein expression in the skeletal muscles.

This hypoxia caused by high altitude is consistent with many situations we encountered in daily life. In this study, the hypoxic plateau environment (HA/HFD group) is hypobaric hypoxia ( $\mathrm{FiO}_{2}$ of $14.07 \%$ ), compared with $20.95 \%$ in the low altitude group (LA/HFD group). Acute hypoxia exposure suppresses appetite and energy intake; however, as the duration of hypoxic exposure increases, appetite gradually improves [38-40]. Studies have reported that appetite suppression may be alleviated during chronic exposure to altitudes below 5,000 m [41]. Moreover, Karl et al. [40] showed that compared to sea level volunteers, the appetite of high-altitude hypoxia volunteers was not significantly different by day 18 , despite substantial weight loss. Lippl et al. [42] indicated that high-altitude living lowered body weight in obese subjects. Kayser and Verges [43] showed that a long duration of high-altitude exposure is often accompanied by weight loss. In the current study, we showed that acute hypoxia suppressed food intake; however, after 2 weeks food intake gradually improved in mice exposed to hypoxia at high altitudes. Furthermore, the body weight of mice fed an HFD was significantly decreased under hypoxia exposure compared to in the LA group (normoxia), particularly after 6 weeks.

The HFD in this experiment contained 35\% fat (60\% of energy). Lipids are long-term energy sources that last longer and increase the satiety of animals [44]. Thus, mice fed an HFD (LA/HFD and HA/HFD groups) showed lower total food intake compared to mice fed the normal diet (control group). Furthermore, according to energy efficiency calculations [45], the energy efficiency was increased in the LA/HFD and HA/HFD groups compared to the control group. Our results also demonstrated that the energy efficiency was significantly decreased under acute hypoxia, whereas energy efficiency in mice fed an HFD improved over time at high-altitude hypoxia. Although the body weight of the HA/HFD group was obviously decreased compared to that of the LA/HFD group after 6 weeks, food intake and energy efficiency were not significantly different. Importantly, as mice in all groups were housed at the same temperature, any potential biases should be equal in each group [45-47]. Thus, the 
Song et al.: High Altitude and Insulin Sensitivity

effect of high-altitude hypoxia on body weight was not due to decreased food intake or energy efficiency.

The duration of exposure to high altitude and pattern of hypoxia exposure may influence the effects on glucose homeostasis and insulin sensitivity. Most studies revealed that glycemia was lower at higher altitudes compared to lower altitudes [48]. Clinically healthy residents living between 3,000 and 4,500 m exhibited lower fasting blood glucose levels than those living below $500 \mathrm{~m}$ [8]. At low altitude, fasting glucose decreased significantly after exposure to very high altitude for 3-8 weeks [49]. A study of mice breathing hypoxic air $\left(10 \% \mathrm{O}_{2}\right)$ for 4 weeks showed increased insulin sensitivity and a significant decrease in fasting blood glucose [50]. Our study showed that fasting blood glucose and the area under the curve (AUC) of glucose tolerance were clearly decreased in the HA/HFD group after 8 weeks, compared to in the LA/HFD group, as assessed by whole-body insulin sensitivity with the ITT [51]. The HOMA index is [52] is a surrogate measure of insulin sensitivity. Our study indicated that the area under the AUC curve of ITT in the HA/HFD group was significantly smaller than that in the LA/HFD group. These results confirmed the important beneficial effect of prolonged hypoxia on insulin sensitivity.

Mitochondrial dysfunction is closely related to insulin resistance [19]. The skeletal muscle is an important metabolic organ and is involved in insulin resistance resulting from mitochondrial dysfunction and impaired FAO [53]. Reductions in mitochondrial biogenesis and mitochondrial content and size decrease the level of substrate oxidation, particularly of FAO, leading to lipid deposition and inhibition of insulin signaling $[19,54]$, while decreased mitochondrial content in the skeletal muscle and reduced mitochondrial electron transport chain activity have been reported in individuals with obesity and type 2 diabetes [55]. The mitochondrial respiratory control ratio reflects the structural integrity and coupling rate of mitochondria and thus the mitochondrial respiration capacity [56]. A recent study showed that this ratio was reduced in obese women as compared to lean women [57]. In our study, compared to the control group, the mitochondrial content and size in the skeletal muscle of mice fed an HFD was decreased significantly. However, the mitochondrial content and size in the HA/HFD group was higher than that in the LA/HFD group, indicating that hypoxia plays an important role in these effects. Additionally, in our study, high altitude-associated hypoxia improved the mitochondrial respiratory control ratio in the skeletal muscle of mice with HFD-induced obesity, regardless of whether the substrate was octanoylcarnitine and malate or malate and glutamate. The coupling efficiency in the HA/HFD group was higher than in the LA/HFD group, indicating that mitochondria can better utilize oxygen under high-altitude hypoxia.

AMPK is a receptor of hypoxic energy and regulator of metabolic homeostasis. AMPK is activated and phosphorylated under hypoxia, further enhancing mitochondrial biogenesis and FAO [25]. PGC-1 $\alpha$ is an important regulator of mitochondrial biogenesis [58]. Nrf1 is a $P G C-1 \alpha$ target gene, which encodes a transcription factor that stimulates nuclear-encoded mitochondrial Tfam genes [59]. Tfam is mainly localized in mitochondria and binds to the D-loop of the mitochondrial genome to increase mitochondrial gene transcription and mtDNA replication [60]. Our study showed that AMPK was activated and phosphorylated at high altitudes under hypoxia. In the HA/HFD group, p-AMPK expression was increased significantly compared to in the LA/HFD group. p-AMPK promoted the PGC- $1 \alpha /$ Nrf1/Tfam pathway. Similarly, expression of the 3 genes in the HA/HFD group was higher than in the LA/HFD group, indicating that hypoxia promotes mitochondrial biogenesis via AMPK activation.

Mitochondrial dysfunction causes lipid accumulation, which is a major contributor to the development of insulin resistance [19]. However, an increase in mitochondrial FAO can restore insulin sensitivity. CPT1 is an important regulator of mitochondrial FAO: AMPK phosphorylates and inactivates the mitochondrial enzyme ACC2 (acetyl-CoA carboxylase 2), which

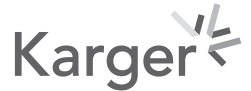


suppresses malonyl CoA expression, whereas CoA in turn promotes the expression of CPT1, which reduces lipid deposition [61]. Our results showed that the FAO-related gene CPT1 in the skeletal muscle was upregulated, whereas fatty synthesis-related genes (ACC2 and Srebp1c) were downregulated under high altitude-induced ambient hypoxia, and that the skeletal muscle triglyceride content was decreased. Our results indicate that FAO was increased under high-altitude hypoxia via AMPK activation.

In addition, mitochondrial dysfunction leads to lipid accumulation, including deposition of metabolically active lipid mediators such as ceramides. Ceramides is an intermediate product of lipid aggregation and an increase in its levels affects AKT in the insulin signaling pathway, decreasing Akt phosphorylation levels, and leading to a decrease in insulin biological effects, promoting insulin resistance [62]. The p-Akt/Akt ratio is an index of activation of the insulin signaling pathway in skeletal muscle [63]. We observed that the p-Akt/Akt ratio in the skeletal muscles were enhanced under high altitude-induced hypoxia, supporting that hypoxia improved insulin signaling in HFD-induced mice by reducing lipid deposition.

Although the relationship between hypoxia and insulin sensitivity has been widely revealed to be associated with skeletal muscle AMPK activation [64-67], this study systematically evaluates the effects of high altitude on reprogramming gene expression in the metabolic pathways in mitochondria and regulating AMPK activation in skeletal muscles from mice fed an HFD. In addition, although other studies have focused on the impacts of transient, short-term, or chronic intermittent hypoxia on insulin sensitivity, we investigated the effects of relatively longer-term exposure to ambient hypoxia caused by high elevation, which more faithfully recapitulates the metabolic benefits of natural environments in patients with obesity residing in high-altitude regions.

In conclusion, we have demonstrated that high altitude-induced ambient hypoxia improved insulin sensitivity in mice with HFD-induced obesity, which was associated with AMPK activation in the mice skeletal muscles, and subsequently enhanced mitochondrial biogenesis, elevated expression of CPT1, increased FAO, and reduced lipid accumulation. These findings provide a molecular explanation for the phenomenon demonstrating that high altitude is associated with a reduced incidence of insulin resistance syndrome in people with obesity.

\section{Statement of Ethics}

All animal experiments involving the use of mice in this study were approved by the Animal Protection and Use Institutions Committee of Qinghai University (Xining, China). All experiments were carried out in accordance with the Animal Management Regulations of the Ministry of Health of China.

\section{Conflict of Interest Statement}

The authors declare that they have no competing interests.

\section{Funding Sources}

This work was supported by a grant from the National Natural Science Foundation of China (No. 31770121).

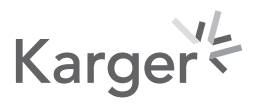




\begin{tabular}{l|l|}
\hline Obes Facts 2020;13:455-472 \\
\hline DOI: 10.1159/000508112 & $\begin{array}{l}\text { ○ 2020 The Author(s). Published by S. Karger AG, Basel } \\
\text { www.karger.com/ofa }\end{array}$ \\
\hline
\end{tabular}

Song et al.: High Altitude and Insulin Sensitivity

\section{Author Contributions}

K.S., Z.B., and R.-L.G. conceived study; K.S. performed most of the experiments and analyzed the data; Y.Z. and Q.G. maintained the animals and collected samples; Z.B. contributed to the experimental design; K.S. and R.-L.G. wrote the manuscript, and R.-L.G. supervised the study. All authors approve the final version of the manuscript.

\section{References}

1 Chandler M, Cunningham S, Lund EM, Khanna C, Naramore R, Patel A, et al. Obesity and associated comorbidities in people and companion animals: a one health perspective. J Comp Pathol. 2017 May;156(4):296309.

2 Saltiel AR, Olefsky JM. Inflammatory mechanisms linking obesity and metabolic disease. J Clin Invest. 2017 Jan; 127(1):1-4.

3 Rahtu-Korpela L, Karsikas S, Hörkkö S, Blanco Sequeiros R, Lammentausta E, Mäkelä KA, et al. HIF prolyl 4-hydroxylase-2 inhibition improves glucose and lipid metabolism and protects against obesity and metabolic dysfunction. Diabetes. 2014 Oct;63(10):3324-33.

4 Barazzoni R, Gortan Cappellari G, Ragni M, Nisoli E. Insulin resistance in obesity: an overview of fundamental alterations. Eat Weight Disord. 2018 Apr;23(2):149-57.

5 Woolcott O0, Gutierrez C, Castillo OA, Elashoff RM, Stefanovski D, Bergman RN. Inverse association between altitude and obesity: a prevalence study among andean and low-altitude adult individuals of Peru. Obesity. 2016 Apr;24(4):929-37.

6 Lopez-Pascual A, Bes-Rastrollo M, Sayón-Orea C, Perez-Cornago A, Díaz-Gutiérrez J, Pons JJ, et al. Living at a Geographically Higher Elevation Is Associated with Lower Risk of Metabolic Syndrome: Prospective Analysis of the SUN Cohort. Front Physiol. 2017 Jan;7:658.

7 Woolcott 00, Castillo OA, Gutierrez C, Elashoff RM, Stefanovski D, Bergman RN. Inverse association between diabetes and altitude: a cross-sectional study in the adult population of the United States. Obesity. 2014 Sep; 22(9):2080-90.

8 Woolcott 00, Ader M, Bergman RN. Glucose homeostasis during short-term and prolonged exposure to high altitudes. Endocr Rev. 2015 Apr;36(2):149-73.

9 Rausch ME, Weisberg S, Vardhana P, Tortoriello DV. Obesity in C57BL/6J mice is characterized by adipose tissue hypoxia and cytotoxic T-cell infiltration. Int J Obes. 2008 Mar;32(3):451-63.

10 Hosogai N, Fukuhara A, Oshima K, Miyata Y, Tanaka S, Segawa K, et al. Adipose tissue hypoxia in obesity and its impact on adipocytokine dysregulation. Diabetes. 2007 Apr;56(4):901-11.

11 Eltzschig HK, Carmeliet P. Hypoxia and inflammation. N Engl J Med. 2011 Feb;364(7):656-65.

12 Nizet V, Johnson RS. Interdependence of hypoxic and innate immune responses. Nat Rev Immunol. 2009 Sep; 9(9):609-17.

13 Trayhurn P. Hypoxia and adipocyte physiology: implications for adipose tissue dysfunction in obesity. Annu Rev Nutr. 2014;34(1):207-36.

14 Wang Y, Wen L, Zhou S, Zhang Y, Wang XH, He YY, et al. Effects of four weeks intermittent hypoxia intervention on glucose homeostasis, insulin sensitivity, GLUT4 translocation, insulin receptor phosphorylation, and Akt activity in skeletal muscle of obese mice with type 2 diabetes. PLoS One. 2018 Sep;13(9):e0203551.

15 Navarrete-Opazo A, Mitchell GS: Therapeutic potential of intermittent hypoxia: a matter of dose. Am J Physiol Regul Integr Comp Physiol. 2014 Nov 15;307(10):R1181-97.

16 Lempesis IG, van Meijel RL, Manolopoulos KN, Goossens GH. Oxygenation of adipose tissue: A human perspective. Acta Physiol. 2020 Jan;228(1):e13298.

17 Yazıcı D, Sezer H. Insulin Resistance, Obesity and Lipotoxicity. Adv Exp Med Biol. 2017;960:277-304.

18 Kim JA, Wei Y, Sowers JR. Role of mitochondrial dysfunction in insulin resistance. Circ Res. 2008 Feb;102(4): 401-14.

19 Montgomery MK, Turner N. Mitochondrial dysfunction and insulin resistance: an update. Endocr Connect. 2015 Mar;4(1):R1-15.

20 Wang $\mathrm{CH}$, Wang CC, Wei YH. Mitochondrial dysfunction in insulin insensitivity: implication of mitochondrial role in type 2 diabetes. Ann N Y Acad Sci. 2010 Jul;1201(1):157-65.

21 DeFronzo RA, Tripathy D. Skeletal muscle insulin resistance is the primary defect in type 2 diabetes. Diabetes Care. 2009 Nov;32 Suppl 2:S157-63.

22 Wu H, Ballantyne CM. Skeletal muscle inflammation and insulin resistance in obesity. J Clin Invest. 2017 Jan; 127(1):43-54.

23 Bonen A, Parolin ML, Steinberg GR, Calles-Escandon J, Tandon NN, Glatz JF, et al. Triacylglycerol accumulation in human obesity and type 2 diabetes is associated with increased rates of skeletal muscle fatty acid transport and increased sarcolemmal FAT/CD36. FASEB J. 2004 Jul;18(10):1144-6.

24 Bournat JC, Brown CW. Mitochondrial dysfunction in obesity. Curr Opin Endocrinol Diabetes Obes. 2010 Oct; 17(5):446-52. 


\begin{tabular}{l|l}
\hline \multicolumn{2}{l}{ Obes Facts 2020;13:455-472 } \\
\hline DOI: $10.1159 / 000508112$ & $\begin{array}{l}\text { (c) 2020 The Author(s). Published by S. Karger AG, Basel } \\
\text { www.karger.com/ofa }\end{array}$ \\
\hline
\end{tabular}

Song et al.: High Altitude and Insulin Sensitivity

25 Herzig S, Shaw RJ. AMPK: guardian of metabolism and mitochondrial homeostasis. Nat Rev Mol Cell Biol. 2018 Feb;19(2):121-35.

26 Lantier L, Fentz J, Mounier R, Leclerc J, Treebak JT, Pehmøller C, et al. AMPK controls exercise endurance, mitochondrial oxidative capacity, and skeletal muscle integrity. FASEB J. 2014 Jul;28(7):3211-24.

27 Jäger S, Handschin C, St-Pierre J, Spiegelman BM. AMP-activated protein kinase (AMPK) action in skeletal muscle via direct phosphorylation of PGC-1alpha. Proc Natl Acad Sci USA. 2007 Jul;104(29):12017-22.

28 Reznick RM, Shulman GI. The role of AMP-activated protein kinase in mitochondrial biogenesis. J Physiol. 2006 Jul;574(Pt 1):33-9.

29 Kelly DP, Scarpulla RC. Transcriptional regulatory circuits controlling mitochondrial biogenesis and function. Genes Dev. 2004 Feb;18(4):357-68.

30 Ekstrand MI, Falkenberg M, Rantanen A, Park CB, Gaspari M, Hultenby K, et al. Mitochondrial transcription factor A regulates mtDNA copy number in mammals. Hum Mol Genet. 2004 May;13(9):935-44.

31 Al Dera H, Eleawa SM, Al-Hashem FH, Mahzari MM, Hoja I, Al Khateeb M. Enhanced hepatic insulin signaling in the livers of high altitude native rats under basal conditions and in the livers of low altitude native rats under insulin stimulation: a mechanistic study. Arch Physiol Biochem. 2017 Jul;123(3):145-58.

32 Horscroft JA, Kotwica AO, Laner V, West JA, Hennis PJ, Levett DZ, et al. Metabolic basis to Sherpa altitude adaptation. Proc Natl Acad Sci USA. 2017 Jun;114(24):6382-7.

33 Livak KJ, Schmittgen TD. Analysis of relative gene expression data using real-time quantitative PCR and the 2(-Delta Delta C(T)) Method. Methods. 2001 Dec;25(4):402-8.

34 Solaini G, Baracca A, Lenaz G, Sgarbi G. Hypoxia and mitochondrial oxidative metabolism. Biochim Biophys Acta. 2010 Jun-Jul;1797(6-7):1171-7.

35 Peacock AJ. ABC of oxygen: oxygen at high altitude. BMJ. 1998 Oct;317(7165):1063-6.

36 O'Neill HM, Holloway GP, Steinberg GR. AMPK regulation of fatty acid metabolism and mitochondrial biogenesis: implications for obesity. Mol Cell Endocrinol. 2013 Feb;366(2):135-51.

37 Manning BD, Toker A. AKT/PKB Signaling: navigating the Network. Cell. 2017 Apr;169(3):381-405.

38 Debevec T. Hypoxia-Related Hormonal Appetite Modulation in Humans during Rest and Exercise: mini Review. Front Physiol. 2017 May; 8:366.

39 Matu J, O'Hara J, Hill N, Clarke S, Boos C, Newman C, et al. Changes in appetite, energy intake, body composition, and circulating ghrelin constituents during an incremental trekking ascent to high altitude. Eur J Appl Physiol. 2017 Sep;117(9):1917-28.

40 Karl JP, Cole RE, Berryman CE, Finlayson G, Radcliffe PN, Kominsky MT, et al. Appetite suppression and altered food preferences coincide with changes in appetite-mediating hormones during energy deficit at high altitude, but are not affected by protein intake. High Alt Med Biol. 2018 Jun;19(2):156-69.

41 Debevec T, Simpson EJ, Mekjavic IB, Eiken O, Macdonald IA. Effects of prolonged hypoxia and bed rest on appetite and appetite-related hormones. Appetite. 2016 Dec;107:28-37.

42 Lippl FJ, Neubauer S, Schipfer S, Lichter N, Tufman A, Otto B, et al. Hypobaric hypoxia causes body weight reduction in obese subjects. Obesity. 2010 Apr;18(4):675-81.

43 Kayser B, Verges S. Hypoxia, energy balance and obesity: from pathophysiological mechanisms to new treatment strategies. Obes Rev. 2013 Jul;14(7):579-92.

44 Kodde IF, van der Stok J, Smolenski RT, de Jong JW. Metabolic and genetic regulation of cardiac energy substrate preference. Comp Biochem Physiol A Mol Integr Physiol. 2007 Jan;146(1):26-39.

45 Seo S, Lee MS, Chang E, Shin Y, Oh S, Kim IH, et al. Rutin increases muscle mitochondrial biogenesis with AMPK activation in high-fat diet-induced obese rats. Nutrients. 2015 Sep;7(9):8152-69.

46 Caffin F, Prola A, Piquereau J, Novotova M, David DJ, Garnier A, et al. Altered skeletal muscle mitochondrial biogenesis but improved endurance capacity in trained OPA1-deficient mice. J Physiol. 2013 Dec;591(23): 6017-37.

47 White JP, Puppa MJ, Sato S, Gao S, Price RL, Baynes JW, et al. IL-6 regulation on skeletal muscle mitochondrial remodeling during cancer cachexia in the ApcMin/+ mouse. Skelet Muscle. 2012 Jul;2(1):14.

48 Holden JE, Stone CK, Clark CM, Brown WD, Nickles RJ, Stanley C, et al. Enhanced cardiac metabolism of plasma glucose in high-altitude natives: adaptation against chronic hypoxia. J Appl Physiol. 1995 Jul;79(1):222-8.

49 Benso A, Broglio F, Aimaretti G, Lucatello B, Lanfranco F, Ghigo E, Grottoli S: Endocrine and metabolic responses to extreme altitude and physical exercise in climbers. Eur J Endocrinol. 2007 Dec;157(6):733-40.

50 Lee EJ, Alonso LC, Stefanovski D, Strollo HC, Romano LC, Zou B, et al. Time-dependent changes in glucose and insulin regulation during intermittent hypoxia and continuous hypoxia. Eur J Appl Physiol. 2013 Feb;113(2): 467-78.

51 Grulet H, Durlach V, Hecart AC, Gross A, Leutenegger M. Study of the rate of early glucose disappearance following insulin injection: insulin sensitivity index. Diabetes Res Clin Pract. 1993 Jun;20(3):201-7.

52 Matthews DR, Hosker JP, Rudenski AS, Naylor BA, Treacher DF, Turner RC. Homeostasis model assessment: insulin resistance and beta-cell function from fasting plasma glucose and insulin concentrations in man. Diabetologia. 1985 Jul;28(7):412-9.

53 Aguer C, Harper ME. Skeletal muscle mitochondrial energetics in obesity and type 2 diabetes mellitus: endocrine aspects. Best Pract Res Clin Endocrinol Metab. 2012 Dec;26(6):805-19.

54 Malik AN, Czajka A. Is mitochondrial DNA content a potential biomarker of mitochondrial dysfunction? Mitochondrion. 2013 Sep;13(5):481-92. 
Song et al.: High Altitude and Insulin Sensitivity

55 Ritov VB, Menshikova EV, Azuma K, Wood R, Toledo FG, Goodpaster BH, et al. Deficiency of electron transport chain in human skeletal muscle mitochondria in type 2 diabetes mellitus and obesity. Am J Physiol Endocrinol Metab. 2010 Jan;298(1):E49-58.

56 Ioja S, Singamsetty S, Corey C, Guo L, Shah F, Jurczak MJ, et al. Nocturnal hypoxia improves glucose disposal, decreases mitochondrial efficiency, and increases reactive oxygen species in the muscle and liver of C57BL/6 J mice independent of weight change. Oxid Med Cell Longev. 2018 Feb 4;2018:9649608.

57 Konopka AR, Asante A, Lanza IR, Robinson MM, Johnson ML, Man CD. Defects in mitochondrial efficiency and H2O2 emissions in obese women are restored to a lean phenotype with aerobic exercise training. Diabetes. 2015 Jun;64(6):2104-15.

58 Jornayvaz FR, Shulman GI. Regulation of mitochondrial biogenesis. Essays Biochem. 2010;47:69-84.

59 Morino K, Petersen KF, Shulman GI. Molecular mechanisms of insulin resistance in humans and their potential links with mitochondrial dysfunction. Diabetes. 2006 Dec;55 Suppl 2:S9-15.

60 Scarpulla RC. Nuclear control of respiratory gene expression in mammalian cells. J Cell Biochem. 2006 Mar; 97(4):673-83.

61 Hoehn KL, Turner N, Swarbrick MM, Wilks D, Preston E, Phua Y, et al. Acute or chronic upregulation of mitochondrial fatty acid oxidation has no net effect on whole-body energy expenditure or adiposity. Cell Metab. 2010 Jan;11(1):70-6.

62 Hsieh CT, Chuang JH, Yang WC, Yin Y, Lin Y. Ceramide inhibits insulin-stimulated Akt phosphorylation through activation of Rheb/mTORC1/S6K signaling in skeletal muscle. Cell Signal. 2014 Jul;26(7):1400-8.

63 Dongiovanni P, Ruscica M, Rametta R, Recalcati S, Steffani L, Gatti S, et al. Dietary iron overload induces visceral adipose tissue insulin resistance. Am J Pathol. 2013 Jun;182(6):2254-63.

64 Thomas A, Belaidi E, Moulin S, Horman S, van der Zon GC, Viollet B, et al. Chronic intermittent hypoxia impairs insulin sensitivity but improves whole-body glucose tolerance by activating skeletal muscle AMPK. Diabetes. 2017 Dec;66(12):2942-51.

65 Lu H, Gao Z, Zhao Z, Weng J, Ye J. Transient hypoxia reprograms differentiating adipocytes for enhanced insulin sensitivity and triglyceride accumulation. Int J Obes. 2016 Jan;40(1):121-8.

66 Ban JJ, Ruthenborg RJ, Cho KW, Kim JW. Regulation of obesity and insulin resistance by hypoxia-inducible factors. Hypoxia. 2014 Nov; 2:171-83.

67 Lecoultre V, Peterson CM, Covington JD, Ebenezer PJ, Frost EA, Schwarz JM, et al. Ten nights of moderate hypoxia improves insulin sensitivity in obese humans. Diabetes Care. 2013 Dec;36(12):e197-8. 